\title{
DISTAL HYPOSPADIAS;
}

\section{BARCAT-REDMAN URETHROPLASTY}

\author{
DR. MUHAMMAD IQBAL \\ Assistant Professor Urology \\ C.M.C. Teaching Hospital, Larkana
}

\section{DR. NISAR AHMED}

District Urologist

Civil Hospital Dadu

\section{DR. ABDUL RASHEED}

Associate Professor Urology

C.M.C. Teaching Hospital, Larkana

\section{Dr. Malik Hussain}

Associate Professor Urology

C.M.C. Teaching Hospital, Larkana

\section{Dr. Tufail Ahmed}

Assistant Professor Urology

Civil Hospital Sukkur

\section{Dr. Amanullah}

Assistant Professor Urology

C.M.C. Teaching Hospital, Larkana

\section{Dr. Masud Malik \\ Assistant Professor Urology \\ Teaching Hospital, Abbotabad.}

Article Citation:

Iqbal M, Ahmed N, Rasheed A, Hussain M, Ahmed T, Amanullah, Malik M. Distal hypospadias; Barcat-redman urethroplasty. Professional Med J Jun 2009; 16(2): 247-251.

ABSTRACT... Objective: To assess the efficacy, safety and complication of Barcat_Redman urethroplasty technique in the management of distal hypospadias. Place of Study: Prospective study was completed at Urology Department, Services Hospital Lahore and larkana from 1998 to 2007. Material and Methods: Fifty patients of distal hypospadias were selected from the Urology Department of Services Hospital Lahore and Larkana for Barcat_Redman urethroplasty technique. Results: Age of the patients range from 5 to 25 years. the mean age was 11 years. Forty $(80 \%)$ patients belonged to urban areas while $10(20 \%)$ were of rural areas.All the patients presented with dystopia of external urethral meatus and chordee (ventral curvature) while $25(50 \%)$ presented wih misdirected stream, $3(5 \%)$ spraying of urine and $3(5 \%)$ narrow stream . The subcoronal type of distal hypospadias was commonly seen in our study. forty $(80 \%)$ patients had subcoronal and $10(20 \%)$ distal penile urethral opening. Following barcat-redman technique $35(70 \%)$ patients had good result and $8(16 \%)$ patients were declared as fair result while $4(14 \%)$ decleared failure. The overall morbidity rate was $30 \%$ while hospital stay was 3 days. Conclusion: Barcat-Redman urethroplasty technique is simple, less time consuming and has better success rate for the management of Distal hypospadias.

Key words: Distal Hypospadias, Barcat-Redman Technique

\section{INTRODUCTION}

Hypospadias is a congenital malformation of the urethra in which external urethral meatus opens on the ventral surface of the penis and it is associated with absence of distal urethra and corpus spongiosum. This result in incomplete fusion of urethral folds ${ }^{1}$. More than 200 methods of corrective surgery for hypospadias have

been described in various books.

Article received on:

Accepted for Publication:

Received after proof reading:

Correspondence Address:

Dr. Nisar Ahmed Shaikh

Civil Hospital Dadu, Sindh

drnisarshaikh@yahoo.com
$16 / 02 / 2009$

$18 / 03 / 2009$

06/05/2009 
Despite the large number of operative techniques for hypospadias repair, the complication rate is high.

The reported complicated rate was $10-15 \%^{1,2}$. These all forms of hypospadias continue to challenge the urologist. The repair of hypospadias may be either multistaged or single stage repair. In multistaged repair, the tube urethroplasty of theirsch. Duplay of the buried skin strip technique of Denis Brown are in common practice ${ }^{3}$. In this staged repair, the chordee is released first (orthroplasty) and urethral reconstruction is done on a second stage after an interval of 6 to 12 weeks. The main disadvantages of multistaged repair are high morbidity, longer exposure to anaesthesia, inconvenience to the patient and improper blood supply of scared skin from previous surgical procedure ${ }^{4}$. The single stage was popularized nearly two decades ago with simultaneous introduction of the technique of Devine and Howerton in 1961 in this single stage repair the chordee correction and urethral reconstruction is carried out in same sitting.

Single stage repair is preferred to multistaged repair because of the advantage of less morbidity, short exposure to anaesthesia, good cosmetic results and unscarred skin $^{2,4}$. Chordee can be perfectly released after introduction of an artificial erection technique. urethroplasty can be performed using penile or preputial skin or a free skin graft, buccal or bladder mucosa ${ }^{1,3}$.

Barcat-Redman technique is a modification of mathiue procedure in which glans flaps are mobilized in addition to parameatal base flap. This technique is applied to a wide range of hypospadias deformity with decrease incidence of fistula formation. Cosmetic and functional results are excellent with only $3.5 \%$ of the patients requiring reoperation ${ }^{5}$.

\section{AIMS AND OBJECTIVES OF STUDY}

The study was carried out to assess the efficacy , safety and complications of Bacrat - Redman Technique.

\section{MATERIAL AND METHODS}

The study was completed at Urology Department Services Hospital Lahore and Larkana from 1998 to 2007. All patients were investigated like Haemoglobin $(\mathrm{Hb} \%)$, total leukocyte count (TLC), differential leukocyte count (DLC), erytherocyte sedimentation rate (ESR), urinalysis, urine culture (if required), blood urea (if required), serum creatinine (if required), IVU (if required) and Ultrasound of urinary tract. After evaluation of patients, the procedure was performed under general anaesthesia. All the patients were placed in supine position. Preoperative antibiotic was given one hour before operation. The procedure was carried out in single stag. In this procedure orthoplasty and urethroplasty were carried out in same sitting. In BARCAT-REDMAN technique stay suture was applied to the glans and tourniquet at the root of penis. Proximal and distal full skin flaps were created in equal length including urethral groove. Fibrous plaque distal to urethral opening responsible for chordee was completely excised, chordee was checked by infiltrating normal saline in corpora. Urethra proximal to hypospadias opening was extensively mobilized to gain length. glandular wings were developed by creating a deep cleft in the glans. ventral and dorsal flaps were sutured using 4/0 vicryl (polyglactin), the urethral extension was laid into the split glans and meatus was brought to the tip. After that tourniquet was removed and haemostasis was secured. At the end glans wings were closed with skin closure over the tube with $4 / 0$ vicryl which was changed 48 hours after surgery using sofratule (Fig3). Patients were called on 10th operative day for removal of stent.

Patients were advised to visit out-patient department at the 3rd month after surgery.

At each visit history was taken and systemic and local examination were done for any urethral fistula, rotational deformity, disruption or stricture formation.

Success of procedure assessed by following criteria.

$\begin{array}{ll}\text { a. } & \text { good = tube patent with no fistula } \\ \text { b. } & \text { fair = tube patent with fistula } \\ \text { c. } & \text { failure = tube disruption }\end{array}$

\section{CRITERIA FOR EXCLUSION FROM THE STUDY}

1. previous history of surgery for hypospadias.

2. patients having proximal penile and posterior hypospadias.

3. micro penis and ambigous genitalia.

4. patients wihtout chordee. 


\section{RESULTS}

Age of the patients range from 5 to 25 years, the mean age was 11 years. 40(80\%) patients belonged to urban areas while $10(20 \%)$ were of rural areas. All the patients presented with dystopia of external urethral meatus and chordee (ventral curvature). $25(50 \%)$ presented wih misdirected stream, $3(5 \%)$ spraying of urine and $3(5 \%)$ narrow stream. The subcoronal type of distal hypospadias was commonly seen in our study. Forty $(80 \%)$ patients had subcoronal and $10(20 \%)$ distal penile urethral opening. All the patients were had distal type of hypospadias associated with chordee.

Following barcat-redman technique $35(70 \%)$ patients had good result and $5(16 \%)$ patients were declared as fair while four (14\%) patients failured (Fig1). The overall morbidity rate was $30 \%$ while hospital stay was 3 days. In our study, Barcat-Redman technique, the success rate were $70 \%$ and morbidity rate of Barcat-Redmen Technique were $30 \%$.

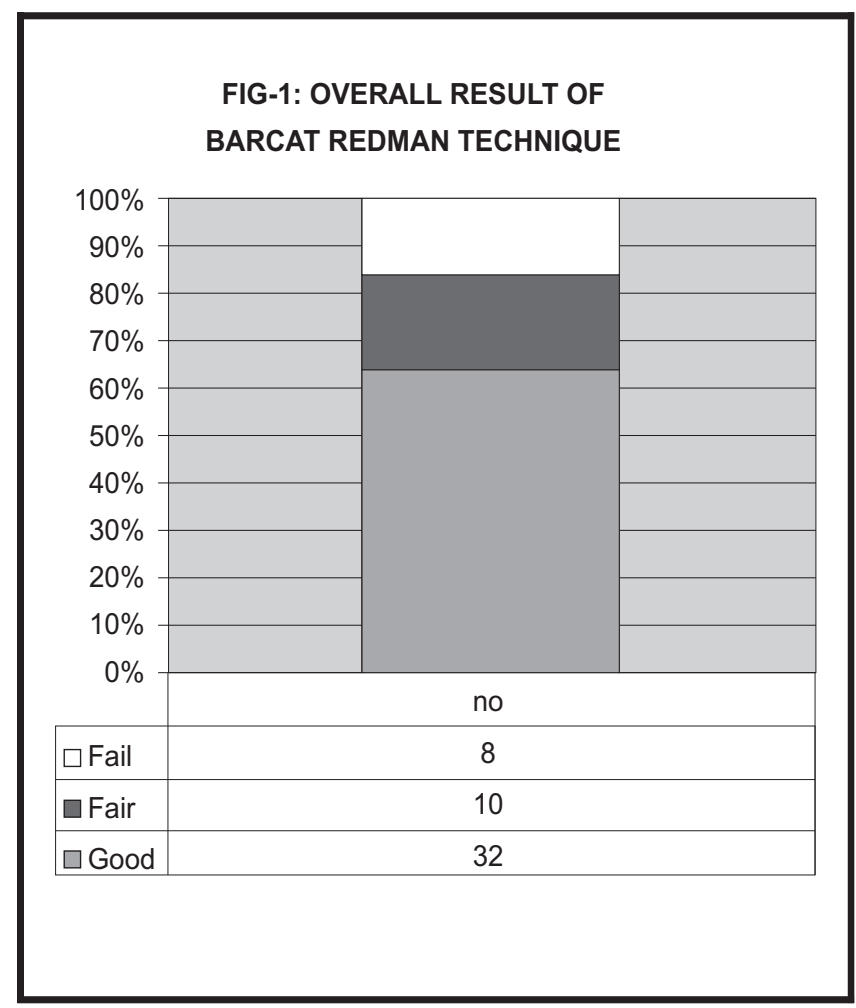

Fig-2. Overall morbidity rate of Barcat Redman technique
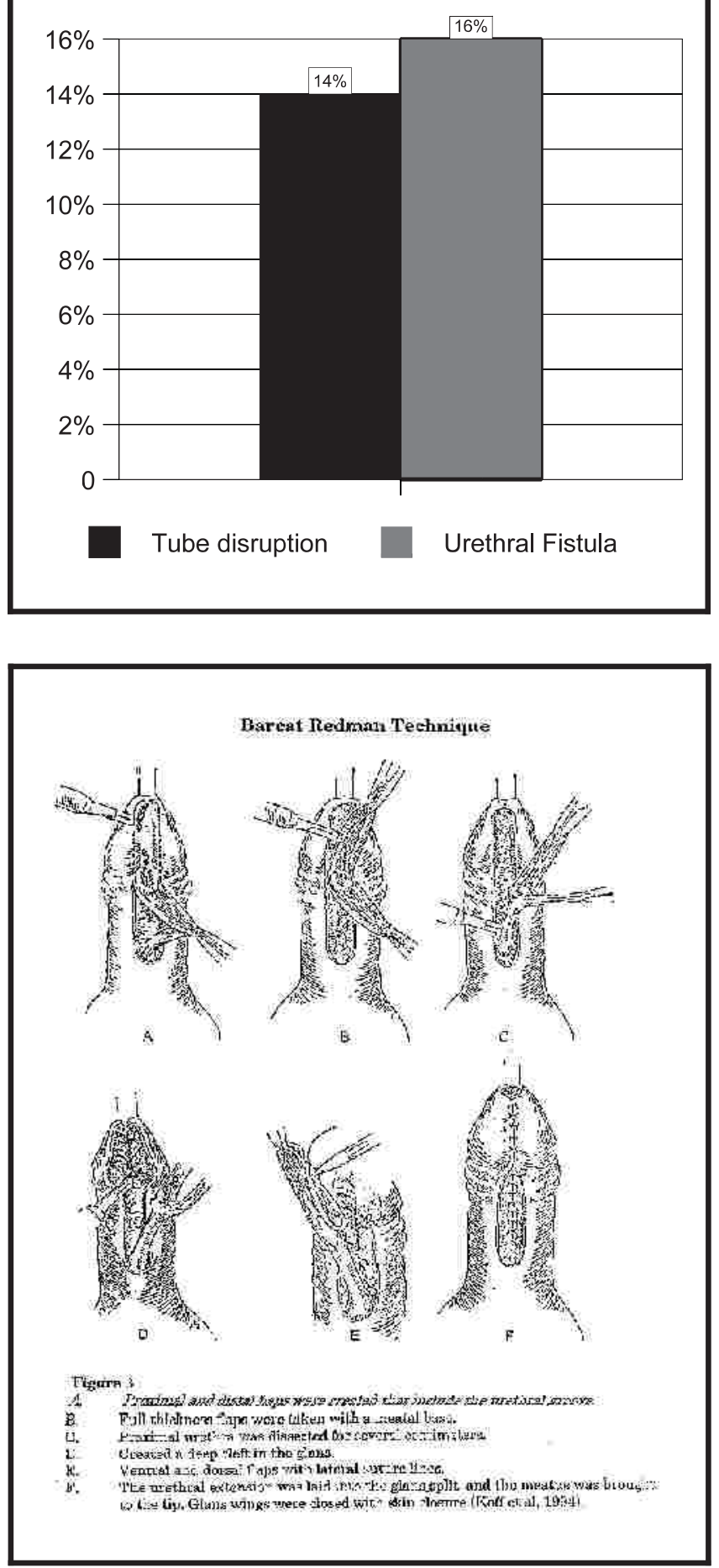


\section{DISCUSSION}

Hypospadias is one of the commonest congenital anomaly of male urethra. the incidence of hypospadias is 1 in 300 live male births. About 6000 boys with hypospadias are born each year in USA. When one child is affected, the next newborn will have $10-15 \%$ more chance. With family history of patients with hypospadias that $21 \%$ had brothers and $7 \%$ had father also affected with hypospadias ${ }^{4,5}$. Above 200 reconstructive procedures for hypospadias have been described. Despite large number of operative techniques for hypospadias repair, the complications rate is very high. The approaches to hypospadias surgery has changed over the past 10 years, since the identification of the urethral plate as an anatomical entity, which has simplified this Surgery ${ }^{7,6}$. A few procedures using the same principles allow a single stage repair in all Cases. These periods mark the history of hypospadias repair, the 19th century, where the principles of the surgery were remarkably good but the technical facilities were insufficient. Finally in 1980s where modern principles were standardized which offers better, functional and cosmetic results ${ }^{7}$. All techniques of hypospadias repair are not in common practice. only a few of these are practiced in most of the centers. The main steps for successful hypospadias surgery are the correction of penile chordee, the reconstruction of missing urethra (urethroplasty) and the covering of the penis and fashioning of the slit shaped urethral meatus ${ }^{5,7}$. Fifty patients were operated and analyzed they belonged to urban as well as rural areas. Age of patients ranged from 5-25 years, the mean age was 11 years. In general, the hypospadias repair is performed when the age is 6-9 months or in older children at the time of referral. Elder et al in (1987) showed that the number of patients repaired at the age ranged from 7-27 years and Hendren et al in 1988 , reported that the number of patients treated the age ranged from 9 months to 22 years. In our study many of the patients came in adult age for infertility having hypospadias. The delay in the treatment was because of fear of surgery embarrassment and ignorance. Patient also came with history of painful erection, penile pain during intercourse or inability to penetrate the vagina which compels the patients to seek treatment ${ }^{7,8}$. in our study subcoronal type of distal hypospadias was commonly seen. Its incidence was $80 \%$. The higher incidence in this study is comparable to other studies.
Welch (1979) reported that is $62 \%$ of the opening was subcoronal and penile while in $20 \%$ was at the penoscrothal angle and is $16 \%$ was in the scrotum or perineum $^{5,7}$. In Barcat-redman technique is a modification of mathiue procedure in which glans flap is mobilized in addition to parameatal base flap. This technique applies to a wide range of hypospadias deformity with decreased incidence of fistula formation. Cosmetic and functional results are excellent with only $3.5 \%$ of the patients requiring reoperation because surgical technique depends on the configuration of glans, depth of the urethral groove, caliber of the urethral meatus and circumcision. The Barcat-Redman technique allows anatomical superior glans reconstruction in distal hypospadias repair. The fistula rate can be reduced by tissue coverage of the neourethra. The single stage repair was popularized nearly two decades ago with simultaneous introduction of the techniques of Devine and Howerton in 1961. in this single stage repair the chordee correction and urethral reconstruction is carried out in same sitting. Single stage is preferred to multistaged repair because of the advantage of less morbidity, short exposure to anaesthesia, good cosmetic results and unscarred $\mathrm{skin}^{9}$. The overall success rate of Barcat-Redman technique was $70 \%$ and other studies showed $96.5 \%$ success. The higher success rate in other study is due to expertly and less post operative wound infection ${ }^{7,8}$. Failure rate was $30 \%$ out of which $14 \%$ had complete disruption of tube while $16 \%$ developed urinary fistulae (Fig2). In another study showed 3.5\% reoperation while $5.0 \%$ developed urinary fistula reported by Barcat ${ }^{9,10}$. The higher incidence of failure in our study probably was due to postoperative infection and lack of very delicated instruments. However the important factors which are responsible for success are use of vascularized tissue, careful tissue handling, non overlapping suture lines, meticulous haemostasis, tension free anastomosis and fine suturing materials and instruments ${ }^{7,11}$.

\section{CONCLUSION}

Barcat-Redman urethroplasty technique is simple, less time consuming and has better success rate for the management of distal hypospadias 


\section{REFERENCES}

1. Barthhold JS, Teer TL, redman JF. Modified Barcat groove technique for hypospadias repair: Experience with 295 case. J urology 1996; 155(5): 1735-7.

2. Broardbent TR and Woolf Rm. Hypospadias: one stage repair. Plastic Reconstruction. Surg 1965; 406-412.

3. Dindar H, CakmaK M, Yucesan S, Barlas M. Distal penile hypospadias repair in children with complete mobilization of pendulous urethra and triangular glandular flap. BJU 1995; 75: 94-95.

4. Gilvernet JM, Cartero P, Carrlph A. new Surgical technique for balanitic hypospadias correction. J Urology 1974; 112: 673 .

5. Goepel M, Otto T, Croft D, Rebben H. Recent consideration for hypospadias repair result of 252 operations from 1985-90. J Urology 1996; 29 (1): 63-66.

6. Joseph VT. One stage repair of hypospadias. Aannals of academy of medicine, Singapore 1983; 51:(3): 195-201.

7. Koff SA, Brinkman J, Deigtton D. Extensive mobilization of the urethral plate and urethra for hypospadias. The modified Barcat technique. J urology 1994; 151:466-69.

8. Mouriquand PDE, Persad R, Sharma S. Hypospadias repair: Current principles and procedures. $\mathrm{Br} \mathrm{J}$ Urol 1995; 76 (3): 9-22.

9. Redman JF. The Barcat balanic groove technique for the repair of distal hypospadias. J Urology 1987; 137: 83-85.

10. Hayashi $Y$, Kojima Y. Current concepts in hypospadias surgery. Int J Urol. 2008 Aug;15(8):651-64. Epub 2008 Jun

11. Ratan SK, Ratan J, Rattan KN. Is tubularization of the mobilized urethral plate a better alternative to tubularization of an incised urethral plate for hypospadias repair? Pediatr Surg Int. 2009 Feb;25(2):185-90.

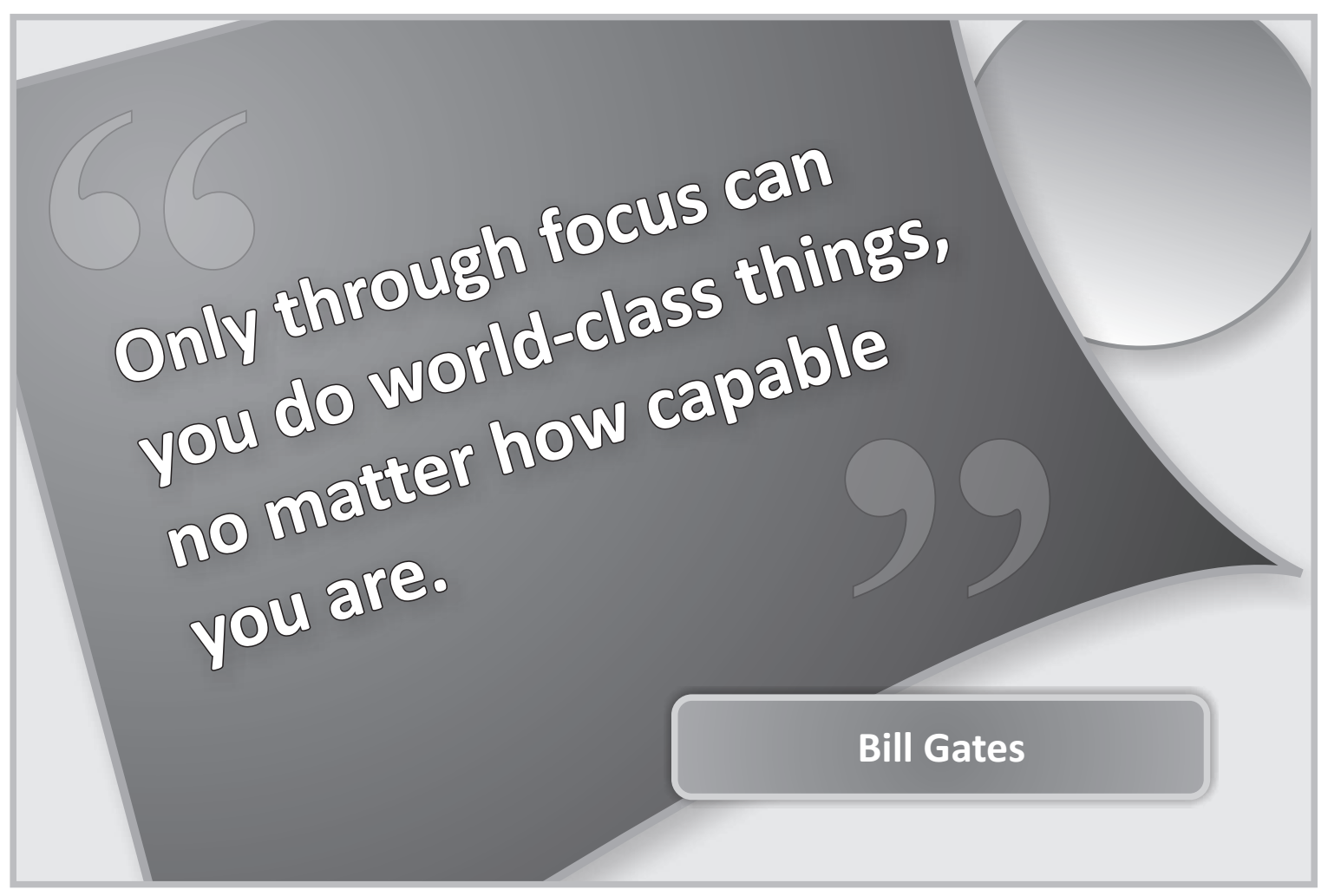

